\title{
Optimal Hedging Strategies for Natural Gas
}

\author{
Changfeng Zhou ${ }^{1} \&$ Huan $\mathrm{Cai}^{2}$ \\ ${ }^{1}$ School of Economic and Management, Zhaoqing University, Guangdong, China \\ ${ }^{2}$ School of English for International Business, Guangdong University of Foreign Studies, Guangdong, China \\ Correspondence: Huan Cai, School of English for International Business, Guangdong University of Foreign \\ Studies, Baiyun Ave., Guangzhou 510420, China. Tel: 86-20-3651-7137. E-mail: \\ 200511468@oamail.gdufs.edu.cn
}

Received: May 9, 2020

Accepted: June 4, 2020

Online Published: June 20, 2020

doi:10.5539/ijef.v12n8p1

URL: https://doi.org/10.5539/ijef.v12n8p1

\begin{abstract}
This study examines the optimal hedge performance between natural gas market and crude oil, ECO, gold and US-bonds markets. To calculate optimal hedge ratios and hedging effectiveness, we apply several multivariate volatility models, namely CCC, DCC, CDCC and bayesDCC. The empirical results show that crude oil is the best asset to hedge natural gas followed by gold and ECO. This is a new result relative to the existing literature on natural gas prices. Additionally, we find that the bayesDCC model has the best performance on optimal hedge ratios (OHRs) calculation in terms of hedging effectiveness. Our findings will hold important financial risk management implications and asset portfolio for those invest in natural gas market.
\end{abstract}

Keywords: natural gas, optimal hedging strategies, hedging effectiveness, multivariate GARCH model

\section{Introduction}

Natural gas is a clean and environmentally friendly high-quality energy source, almost free of sulfur, dust and other harmful substances. Thus, it has become a major energy production in some leading countries. As same as crude oil, natural gas has dual properties acting as both an energy product and a financial product. Although natural gas market has matured greatly over the last decades, the price change and risk exposure of natural gas remain the focus of attention for those market participants. In order to manage the risk of increasing price fluctuations, investors or managers need a deeper understanding of the behavior of gas market volatility and use some reasonable instruments to avoid this risk. In a traditional way, market participants rely mainly on natural gas futures to hedge against spot prices. With the development of natural gas market liberalization and the participation of strategic investors such as hedge funds and investment Banks, which intensify the speculation and price fluctuations of natural gas market. Therefore, traditional ways are not enough to solve its risk hedging problem, it requires more ways to deal with the increasing challenge. In this paper, we try to seek the optimal hedging strategy from a series of natural gas portfolios. To achieve that, we use the multivariate GARCH model to calculate the hedging ratio and hedging efficiency. Furthermore, We compared the hedging performance of different models with different portfolios, as in Chang et al. (2011).

In response, several literatures have attempted to explain the volatility spillovers, dynamic linkages and risk transmission between natural gas and other markets such as crude oil, stocks. Some of notable studies are (Susmel \& Thompson, 1997; Nick \& Thoenes, 2014; Van Goor \& Scholtens, 2014; Ergen \& Rizvanoghlu, 2016; Chang et al., 2018; Hailemariamcs \& Smyth, 2019; Wang et al., 2019) and (Egging \& Holz, 2016; Lin et al., 2019). Most of these studies are focus on the volatility spillovers from other financial markets to the natural gas market or the determinants of natural gas return volatility (e.g. supply shocks, demand changes, new technologies, climate change, weather, energy policies). Hedging management is a key issue for natural gas investment, but we find only a few papers that explicitly calculate hedge ratios for natural gas portfolios. Brinkmann and Rabinovitch (1995) examine the influence of transportation limitations on the hedging effectiveness for the different NYMEX gas future contracts. They find that the NYMEX contract is an effective hedging instrument for natural gas spot, which can be sold into pipelines for consumption in different states of United States. Lin and Li (2015) investigate optimal hedging strategies based on spillover effects which takes into account regional segmentation and natural gas pricing mechanisms, and compares the spillovers effect in the United States, Europe, and Japan. Mart'inez and Torr'o (2015) find that the natural gas portfolios has a higher 
hedging effectiveness when seasonal factors are considered. Ghoddusi and Emamzadehfard (2017) examine the multiple characteristics of hedging performances in United States natural gas market, and find that the longer maturity contracts can improve the hedging effectiveness. Lin et al. (2019) investigate the hedging strategies and risk transmission between natural gas market and stock market, their result shows that investors should hold the long position on stocks to reduce their portfolio risk. Although previous literature shows that the linkage of natural gas with other financial assets regarding dynamic correlations, determinants of volatility spillovers and risk transmission, the optimal hedging strategy of natural gas is rarely discussed, especially the cross-hedging strategy with other financial assets. In this paper, we extend the existing literature of the hedging strategies on natural gas in several ways. We consider a serious of financial assets as the hedging instruments for natural gas. Specifically, this study explores the possibilities of using ECO, gold and bonds to hedge natural gas investments.

To calculate and compare the optimal hedging ratio and optimal hedging portfolio of natural gas, several multivariate GARCH models are used to estimate the variance and covariance for each portfolio. We find that the crude oil is the best instrument to hedge natural gas's price risk followed by gold and ECO. The mean value of the hedge ratio between natural gas and crude oil is approximately equal to 0.4 for each model. Additionally, we also find that bayesDCC model provides the best performance on hedging effectiveness than other multivariate volatility models.

The contributions of this study are as follows. First, we examine the cross-hedge strategies of natural gas with such a basket of financial assets, this has rarely been studied in the previous literature. Second, our empirical results show that crude oil is the best asset to hedge natural gas's price risk followed by GOLD and ECO, this is a new result to the existing literature about natural gas hedging strategy.

The rest of the paper is structured as follows: Section 2 provides a detail on the methodology. Section 3 describes our data and give some summary statistics. Section 4 presents the empirical results and followed by conclusions and discussion in Section 5.

\section{Methodology}

\subsection{Multivariate GARCH Models}

To estimate the variance-covariance matrix and the correlation coefficients of the natural gas portfolio, some multivariate GARCH models are used, namely CCC Engle and Kroner (1995), DCC Engle (2002), cDCC Aielli (2013) and bayes DCC Fioruci et al. (2014). This section presents these models as follows. According to (Engle \& Kroner, 1995), the CCC model is given by:

$$
\begin{aligned}
& y_{t}=E\left(y_{t} \mid F_{t-1}\right)+\varepsilon_{t}, \varepsilon_{t}=D_{t} \eta_{t} \\
& \operatorname{var}\left(\varepsilon_{t} \mid F_{t-1}\right)=D_{t} \Gamma D_{t}
\end{aligned}
$$

where $y_{t}=\left(y_{1 t}, \cdots, y_{m t}\right)^{\prime}, \eta_{t}=\left(\eta_{1 t}, \cdots, \eta_{m t}\right)^{\prime}$ are random vectors which follows independently and identically distribution (i.i.d), $F_{t}$ denotes the past information available at time t, $D=\operatorname{diag}\left(h^{1 / 2}, \cdots, h^{1 / 2}\right)$ is the conditional variance matrix, where $\mathrm{m}$ is the number of observations, and $t=1, \ldots, n$. Due to $\Gamma=E\left(\eta_{t} \eta_{t-1}^{\prime}\right)=E\left(\eta_{t} \eta_{t}^{\prime}\right)$, the unconditional shocks $\left(\eta_{t}\right)$ is equivalent to the constant conditional covariance matrix of the conditional shocks $\left(\varepsilon_{t}\right)$, where $\Gamma=\left\{\rho_{i j}, \forall i, j=1, \cdots, m\right\}$. The CCC model of Engle and Kroner (1995) assume that the variance of each asset's return follows a univariate GARCH process, which can be written as:

$$
h_{i t}=\omega_{i}+\sum_{j=1}^{r} \alpha_{i j} \varepsilon_{i, t-j}^{2}+\sum_{j=1}^{s} \beta_{i j} h_{i, t-j}
$$

where the parameter $\alpha_{i j}$ represents the short-term persistence shocks to return $i$, or the so-called "ARCH effect", and the parameter $\beta_{i j}$ represents the so-called "GARCH effect". Meanwhile, $\sum_{j=1}^{r} \alpha_{i j}+\sum_{j=1}^{s} \beta_{i j}$ denotes the long-term persistence shocks to return $i$.

The CCC model just can give a constant correlation coefficient, but the correlation between assets should be a 
dynamic process. In order to solve this drawback, Engle (2002) developed a dynamic conditional correlation (DCC) model, which can obtain the dynamic conditional correlation coefficients and covariance matrix. It can be defined as follows:

$$
y_{t} \mid F_{t-1} \sim N\left(0, H_{t}\right) H_{t}=D_{t} \Gamma_{t} D_{t} \eta_{t}=D_{t}^{-1} y_{t}
$$

where $D_{t}=\operatorname{diag}\left(h_{i}^{1 / 2}, h_{j}^{1 / 2}\right)$ denotes the diagonal matrix of conditional variance, $\Gamma_{t}$ denotes the conditional correlation matrix. The conditional variance $h_{i t}$ of each return also follows a univariate GARCH process, and can be given as follows:

$$
\begin{aligned}
& h_{i t}=\omega_{i}+\sum_{k=1}^{p} \alpha_{i k} \varepsilon_{i, t-k}^{2}+\sum_{l=1}^{q} \beta_{i l} h_{i, t-l} \\
& \Gamma_{t}=\left\{\operatorname{diag}\left(Q_{t}\right)^{-1 / 2}\right\} Q_{t}\left\{\operatorname{diag}\left(Q_{t}\right)^{-1 / 2}\right\}
\end{aligned}
$$

where the symmetric positive definite matrix $Q_{t}$ is given by:

$$
Q_{t}=\left(1-\delta_{1}-\delta_{2}\right) \bar{Q}+\delta_{1} \eta_{t-1} \eta_{t-1}^{\prime}+\delta_{2} Q_{t-1}
$$

where $Q_{t}$ represents the conditional covariance matrix of portfolio, and $\bar{Q}$ denotes the conditional covariance matrix. $\delta_{1}$ and $\delta_{2}$ captures the effects from previous standardized shocks and previous dynamic conditional correlations on current dynamic conditional correlation. These two parameters are non-negative scalar parameters, satisfy the condition of $\delta_{1}+\delta_{2}<1$ to guarantee the matrix $Q_{t}$ is positive definite. When $\delta_{1}=\delta_{2}=0$, Eq. (5) transforms to the CCC model.

The estimation procedure of DCC model adopt two-step method based on the logarithmic likelihood function. The first step estimates the univariate GARCH process and the second step estimates the conditional correlation matrix. Aielli (2013) point out the inconsistency problems in the second step estimation of the DCC model. To solve this issue, Aielli (2013) propose the corrected dynamic conditional correlation (cDCC) model, which restores consistency, and suggests a feasible estimation method that is similar to the profile likelihood. In brief, he reformulates the specification of the correlation $Q_{t}$ as follows:

where $\eta^{*}=\operatorname{diag}\left\{Q_{t}\right\}^{1 / 2} \eta_{t}$ denotes the standardized residuals.

$$
Q_{t}=(1-\alpha-\beta) \bar{Q}+\alpha \eta_{t-1}^{*} \eta_{t-1}^{* \prime}+\beta Q_{t-1}
$$

Fioruci $t^{t}$ al. (2014) argue that the traditional DCC model established the likelihood function through the unbiased distribution, which not fully consider the temporal features of financial returns such as peak, fat tail. Moreover, the traditional asymmetric volatility models often fail to capture the skewness of financial return distribution. To solve these issues, Fioruci et al. (2014) develop bayesDCC-Skew model, which adopt a bayesian approach to estimate DCC model with skewed and fat tailed distributions to estimate model parameters.

The bayesDCC model includes a class of flexible multivariate skewed (or t-, GED) distributions in the DCC model context and adopt a fully bayesian approach to estimate all unknown parameters. Accounting to Bauwens and Laurent (2005), the multivariate skewed densities can be written as,

$$
s(x \mid \gamma)=2^{k}\left(\prod_{i=1}^{k} \frac{\gamma_{i}}{1+\gamma_{i}^{2}}\right) f\left(x^{*}\right)
$$

where $f()$ is a symmetric multivariate density, $x^{*}=x_{1}^{*}, \ldots, x_{k}^{*}, x_{i}^{*}=x_{i} / \gamma_{i}$ if $x>0$ and $x_{i}^{*}=x_{i} \gamma_{i}$; if $X_{i}<0, i=1, \ldots, k . \gamma_{i}$ denotes the marginal skewness, and when $\gamma_{i}>1$ (or $\gamma_{i}<1$ ) corresponds to right (or left) marginal skewness. For the bayesian paradigm, we need to specify the prior distributions of all parameters. Fallowing Fioruci et al. (2014), these parameters are assumed to be a priori independent and normally distributed truncated. We specify a GARCH $(1,1)$ model for each conditional variance, i.e.

$$
h_{i i, t}=\omega_{i}+\alpha_{i} y_{t-i}+\beta_{i} h_{i i, t-1}
$$

where $\omega_{i} \sim N\left(\mu_{\omega_{i}}, \sigma_{\omega_{i}}^{2}\right) I_{\left(0<\omega_{i}<1\right)}, \quad \alpha_{i} \sim N\left(\mu_{\alpha_{i}}, \sigma_{\alpha_{i}}^{2}\right) I_{\left(0<\alpha_{i}<1\right)}, \quad \beta_{i} \sim N\left(\mu_{\beta_{i}}, \sigma_{\beta_{i}}^{2}\right) I_{\left(0<\beta_{i}<1\right)}$. The parameters $\theta$ 's posterior distribution $\pi(\theta \mid y)$ is analytically intractable. We then adopt the Markov chain Monte Carlo (MCMC) sampling strategies to obtain samples from the joint posterior distributions. 


\subsection{Optimal Hedge Ratios and Portfolio}

In this section, we calculate the optimal hedge ratios and optimal hedge effectiveness for each portfolio. As we all known, one investor chooses a hedging strategy often reflects their attitudes toward risk preferences and their individual goals. Consider the case of a natural gas investment company, who wants to protect exposure to natural gas price fluctuations. He may choose a portfolio of natural gas and other futures position. The return on the company's portfolio can be given as:

$$
R_{\mathrm{H}, \mathrm{t}}=R_{S, t}-\Upsilon_{t} R_{F, t}
$$

where $R_{H, t}$ is the return on holding the portfolio from $t-1$ to $t, R_{S, t}$ and $R_{F, t}$ refers to the return on holding natural gas and other assets positions from $t-l$ to $t . \gamma$ is the hedge ratio, means the number of natural gas futures contracts that the hedger must sell for each unit of other futures contracts that bear the price risk. According to Johnson (1960) and Kroner and $\mathrm{Ng}$ (1998), conditional on the information set available at time t1, the variance of the returns of the hedged portfolio is given by:

$$
\operatorname{var}\left(R_{H, t} \mid \Omega_{t-1}\right)=\operatorname{var}\left(R_{S, t} \mid \Omega_{t-1}\right)-2 \Upsilon_{t} \operatorname{cov}\left(R_{S, t} R_{F, t} \mid \Omega_{t-1}\right)+\Upsilon_{t}^{2} \operatorname{var}\left(R_{F, t} \mid \Omega_{t-1}\right)
$$

where $\operatorname{var}\left(R_{S, t} \mid \Omega_{-1}\right), \operatorname{var}\left(R_{F, t} \mid \Omega_{-1}\right)$ and $\operatorname{cov}\left(R_{S, t} R_{F, t} \mid \Omega_{-1}\right) \operatorname{cov}\left(R_{S, t} R_{F, t} \mid \Omega_{t-1}\right)$ are the conditional variance and conditional covariance of the natural gas and other asset returns, respectively. Baillie and Myers (1991) define the $O H R_{t}$ as the value of $Y_{t}$ when minimizes the conditional variance (risk) of the hedged portfolio returns as: $\min \Upsilon_{t}\left[\operatorname{var}\left(R_{H, t} \mid \Omega_{-1}\right)\right]$. So, the $O H R_{t}$ conditional on the information available at $t-1$ can be given by:

$$
\Upsilon_{t}^{*} \mid \Omega_{t-1}=\frac{\operatorname{cov}\left(R_{S, t} R_{F, t} \mid \Omega_{t-1}\right)}{\operatorname{var}\left(R_{F, t} \mid \Omega_{t-1}\right)}
$$

For the multivariate conditional model, we can obtain estimates of conditional covariance matrix, the $O H R_{t}$ can be written as follows:

$$
\Upsilon_{t}^{*} \mid \Omega_{t-1}=\frac{h_{S F, t}}{h_{F, t}}
$$

where $h_{S F, t}$ is the conditional variance between natural gas and other asset returns, and $h_{F, t}$ is the conditional variance of natural gas returns. Chen (2007) propose a more accuracy method to compare the performance of OHRs which measured by the variance reduction for any hedged portfolio divided by the unhedged portfolio. This hedging effective index (HE) is given by:

$$
H E=\frac{\operatorname{var}_{\text {unhedged }}-\text { var }_{\text {hedged }}}{\text { var }_{\text {unhedged }}}
$$

where var unhedged is the return variance of unhedged portfolio (i.e., variance of crude oil returns), var hedged $_{\text {. }}$ is the variance of hedged portfolio returns which can be calculated as Eq. (9). The higher value of HE means the higher hedging effectiveness and the larger risk reduction, therefore, one portfolio has a higher HE means it is a superior hedging strategy.

\section{Data}

This study uses the daily data set of natural gas, West Texas Intermediate (WTI)crude oil, WilderHill Clean Energy Index (ECO), gold prices and eCBOT 10-Y US treasures bond. We construct the portfolios of natural gas with crude oil, ECO, gold and bond, and choose the optimal hedging portfolio. For this purpose, we collect the close price of the New York Mercantile Exchange (NYMEX) natural gas and crude oil future contract. The ECO index is the proxy variable of clean energy stocks. Gold often act as a safe-heaven asset and an effective hedging instrument in financial market, and its prices data is the close prices of continuous futures contract in New York Mercantile Exchange (COMEX division). The bond data is obtained from the close prices of eCBOT 10-year US Treasury.

Our sample data cover the period from January 4, 1999 to February 28, 2019. The sample period is depended on the length of ECO index. All data are obtained from the Bloomberg database. We calculate all the return sequences through the first difference of natural logarithmic and multiply by 100 as, , $r_{i, t}=100 *\left(\ln P_{i, t}-\right.$ $P_{i, t-1}$ ) where $P_{i, t}$ and $P_{i, t-1}$ are the close prices in market i at days t and $t-1$, respectively. 
Fig. 1 shows the plots of price and return series of each market. As we can see, the natural gas prices fluctuates more frequently than other markets over the sample period, which is confirmed by the stand deviation of natural gas return in Table 1. This is a good reason for natural gas market participants to use other instruments to hedge their price risk exposure. Additionally, all the return series shows a clear volatility cluster phenomenon and indicates that the appropriateness to use the multivariate volatility models in this paper.
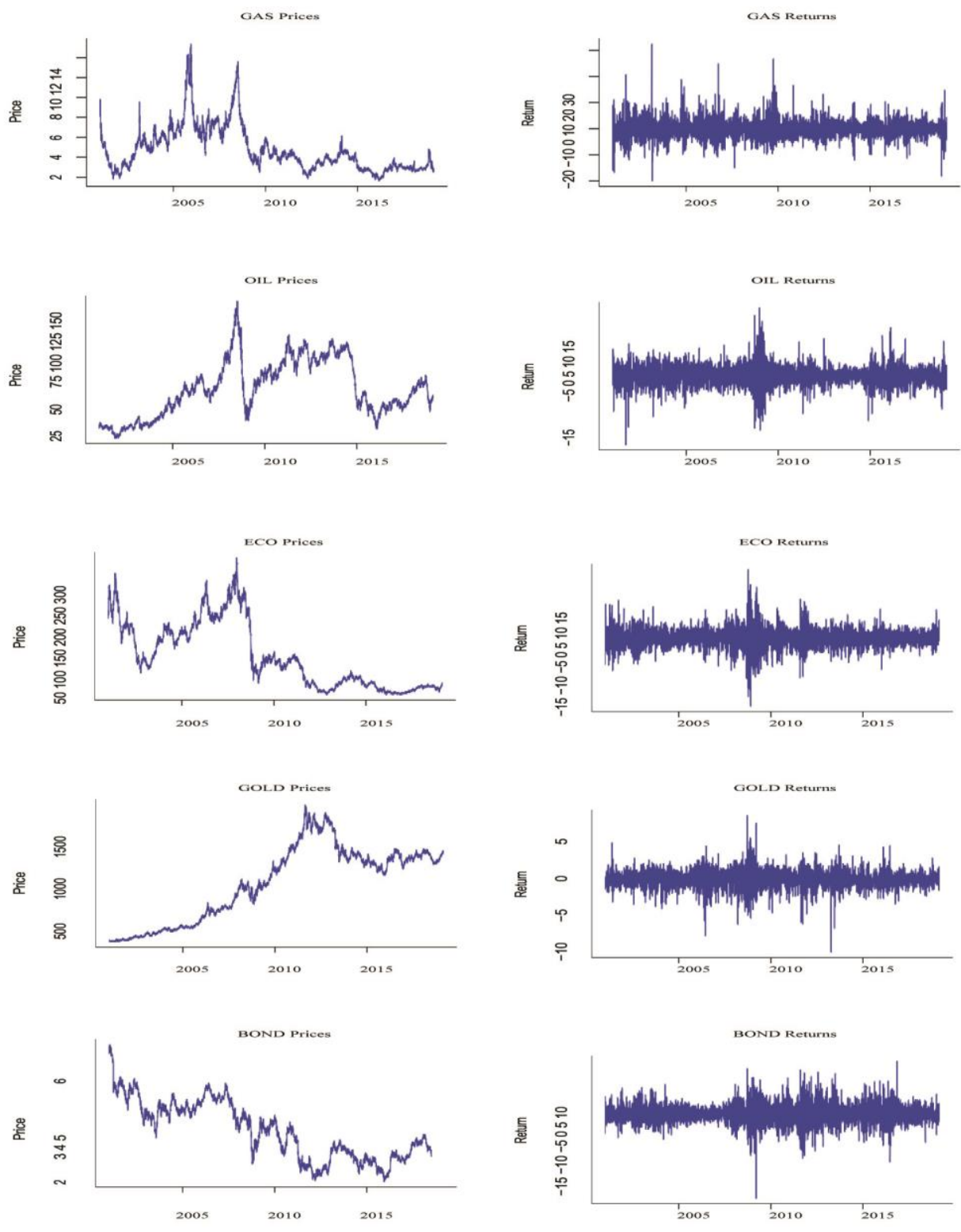

Figure 1. Plots of prices and returns

Table 1 reports the descriptive statistical analysis result of each return series. As it shows, all of the mean values are close to zero for each return series. The standard deviation is ranged from 1.135 to 3.432 , obviously the stand deviation of natural gas returns is much larger than other financial markets and the stand deviation of gold returns is the smallest. It indicates that the price changes of natural gas market more volatile than others, while gold market present a more stable state. The positive skewness of natural gas and bond indicates that there are more extreme values at the right end of the distribution, whereas crude oil, ECO and gold has the opposite extreme value distribution. The kurtosis values of all return series are not subjected to normal distributions, which are further confirmed by Jarque and Bera (1980) tests. The statistics of Engle (1982) ARCH test rejects null hypothesis, it implies the existence of significant heteroscedasticity. The Ljung and Box (1978) Q statistics indicates that the null hypothesis of no autocorrelation up to 1 st and 10th orders is rejected at $5 \%$ significance level except the bond returns (Note 1). Table 1 also presents the results of unit root and stationarity tests. We 
perform these three tests, the null hypothesis are rejected by both Augmented Dickey and Fuller (1979) (ADF) and Phillips and Perron (1988) (PP), whereas that of Kwiatkowski et al. (1992)(KPSS) tests is failure to reject. Hence, the results indicate that all the return series are trend stationarity.

Table 1. Descriptive statistics for each return series

\begin{tabular}{|c|c|c|c|c|c|}
\hline & GAS & OIL & ECO & GOLD & BOND \\
\hline$\overline{\text { Mean }}$ & -0.020 & 0.037 & -0.014 & 0.036 & 0.001 \\
\hline Std.dev. & 3.432 & 2.350 & 2.021 & 1.135 & 1.941 \\
\hline Min & -19.899 & -16.545 & -14.467 & -9.821 & -17.021 \\
\hline Max & 32.435 & 16.410 & 14.520 & 8.625 & 10.686 \\
\hline Skewness & 0.570 & -0.042 & -0.174 & -0.364 & 0.013 \\
\hline Kurtosis & 9.010 & 7.422 & 7.309 & 8.517 & 6.556 \\
\hline J-B & $6326.3 * * *$ & $3307.8 * * *$ & $3159.6 * * *$ & $5236.3 * * *$ & $2138.5^{* * *}$ \\
\hline $\mathrm{ARCH}(1)$ & $25.304 * * *$ & $191.710^{* * *}$ & $337.800^{* * * *}$ & $83.830 * * *$ & $79.686^{* * *}$ \\
\hline $\mathrm{ARCH}(10)$ & $164.347^{* * *}$ & $586.402^{* * *}$ & $1105.000 * * *$ & $216.911^{* * * *}$ & $279.788^{* * *}$ \\
\hline Q (1) & $7.396^{* * *}$ & $6.340^{* *}$ & $6.041 * * *$ & $8.2361^{*}$ & 0.272 \\
\hline $\mathrm{Q}(10)$ & $23.925 * * *$ & $18.714 * * *$ & $29.734 * * *$ & $23.596 * * *$ & $30.288 * * *$ \\
\hline $\mathrm{ADF}$ & $-37.733 * * *$ & $-26.867 * * *$ & $-36.080 * * *$ & $-37.079 * * *$ & $-38.146^{* * *}$ \\
\hline PP & $-66.616^{* * *}$ & $-66.181 * * *$ & $-61.340 * * *$ & $-63.627 * * *$ & $-63.183^{* * *}$ \\
\hline KPSS & 0.035 & 0.036 & 0.048 & 0.063 & 0.024 \\
\hline
\end{tabular}

Note. The Jarque and Bera (1980) statistic tests the null hypothesis of Gaussian distribution. ADF (Dickey \& Fuller, 1979) and PP (Phillips \& Perron, 1988) are denoting the statistics of unit root tests. KPSS (Kwiatkowski et al., 1992) is the stationarity test. ARCH(1) Engle (1982) statistics refers to the return residuals series up to the 1th lags arch effect. Q(1) Ljung and Box (1978) refers to the statistics of the return series up to the lth order serial correlation. *,**,*** indicates the level of significance at $10 \%, 5 \%$ and $1 \%$, respectively.

\section{Empirical Result}

\subsection{Model Estimation Results}

To examine the hedging performance of all portfolio, a key step is to obtain the conditional variance and covariance of the portfolios. As we shown in Table 1, the significance of ARCH effect confirms the appropriateness for using multivariate GARCH models on asset returns volatility. We then employ four different technology to estimate the correlation coefficients and the covariance.

Table 2. Estimated results of CCC models

\begin{tabular}{|c|c|c|c|c|}
\hline & $\omega$ & $\alpha$ & $\beta$ & $\rho$ \\
\hline \multirow[t]{2}{*}{ GAS } & $0.190 * * *$ & $0.086 * * *$ & $0.902 * * *$ & \\
\hline & $(0.057)$ & $(0.014)$ & $(0.014)$ & \\
\hline \multirow[t]{2}{*}{ OIL } & 0.091 & 0.076 ** & $0.907 * * *$ & 0.258 \\
\hline & (0.064) & $(0.025)$ & $(0.035)$ & \\
\hline \multirow[t]{2}{*}{ ECO } & 0.076 & $0.077 *$ & $0.900 * * *$ & 0.036 \\
\hline & $(0.071)$ & $(0.029)$ & $(0.050)$ & \\
\hline \multirow[t]{2}{*}{ GOLD } & $0.011 *$ & $0.042 * * *$ & $0.950^{* * *}$ & 0.073 \\
\hline & $(0.006)$ & $(0.012)$ & $(0.014)$ & \\
\hline \multirow[t]{2}{*}{ BOND } & 0.013 & $0.040 * * *$ & $0.957 * * *$ & 0.014 \\
\hline & $(0.014)$ & 0.010 & $(0.014)$ & \\
\hline
\end{tabular}

Note. The stand error is the Bollerslev and Wooldridge (1992) robust error. $\rho$ denotes the conditional correlation coefficients between natural gas returns and other returns. *, **, *** indicates the level of significance at $10 \%, 5 \%$ and $1 \%$, respectively.

Table 2 reports the estimation results of CCC model for natural gas and other assets. The two lines corresponding to the estimated coefficients of each parameter and their Bollerslev and Wooldridge (1992) robust stand error. The ARCH and GARCH terms for each return series are statistically significance. The ARCH coefficients $(\alpha)$ are less than 0.1 , and the GARCH terms ( $\beta$ ) are close to one. Therefore, the long run persistence indicates that there is a long memory process and when a shock in volatility will continue to have an impact on the volatility over a long horizon. We also find that the estimated conditional correlations of CCC model are not very high. The highest conditional correlation is 0.258 between natural gas returns and crude oil returns. 
Table 3. Estimated results of DCC, cDCC and bayesDCC models

\begin{tabular}{|c|c|c|c|c|c|c|}
\hline & \multicolumn{2}{|l|}{$\underline{\mathrm{DCC}}$} & \multicolumn{2}{|l|}{$\underline{\mathrm{cDCC}}$} & \multicolumn{2}{|c|}{ bayesDCC } \\
\hline & Coeff. & Std. Error & Coeff. & Std. Error & Coeff. & Std. Erro \\
\hline$\omega \mathrm{GAS}$ & $0.168 * * *$ & 0.048 & $0.168 * * *$ & 0.047 & $0.571 * * *$ & 0.096 \\
\hline$\alpha \mathrm{GAS}$ & $0.084 * * *$ & 0.013 & $0.084 * * *$ & 0.012 & $0.111 * * *$ & 0.012 \\
\hline$\beta$ GAS & $0.906 * * *$ & 0.012 & $0.906^{* * *}$ & 0.011 & $0.850 * * *$ & 0.015 \\
\hline$\gamma \mathrm{GAS}$ & & & & & $1.084 * * *$ & 0.025 \\
\hline$\omega \mathrm{OIL}$ & $0.0578 * *$ & 0.032 & $0.058 * * *$ & 0.012 & $0.113 * * *$ & 0.029 \\
\hline$\alpha \mathrm{OIL}$ & $0.065^{* *}$ & 0.020 & $0.065^{* * *}$ & 0.010 & $0.080 * * *$ & 0.011 \\
\hline$\beta \mathrm{OIL}$ & $0.925 * * *$ & 0.024 & $0.925^{* * *}$ & 0.009 & $0.901 * * *$ & 0.014 \\
\hline$\gamma \mathrm{OIL}$ & & & & & $0.922 * * *$ & 0.027 \\
\hline$\omega \mathrm{ECO}$ & $0.061 * * *$ & 0.019 & $0.0615^{* * *}$ & 0.014 & $0.194 * * *$ & 0.030 \\
\hline$\alpha \mathrm{ECO}$ & $0.080 * * *$ & 0.014 & $0.081 * * *$ & 0.012 & $0.121^{* * *}$ & 0.014 \\
\hline$\beta E C O$ & $0.903^{* * *}$ & 0.017 & $0.901 * * *$ & 0.014 & $0.835 * * *$ & 0.018 \\
\hline$\gamma E C O$ & & & & & $0.937 * * *$ & 0.022 \\
\hline$\omega \mathrm{GOLD}$ & $0.010 * *$ & 0.004 & $0.010^{* * *}$ & 0.003 & $0.023 * * *$ & 0.004 \\
\hline$\alpha \mathrm{GOLD}$ & $0.042 * * *$ & 0.009 & $0.042 * * *$ & 0.009 & $0.045^{* * *}$ & 0.006 \\
\hline$\beta G O L D$ & $0.950 * * *$ & 0.009 & $0.950 * * *$ & 0.009 & $0.936^{* * *}$ & 0.009 \\
\hline$\gamma \mathrm{GOLD}$ & & & & & $0.932 * * *$ & 0.031 \\
\hline$\omega \mathrm{BOND}$ & $0.008^{* *}$ & 0.003 & $0.008 * * *$ & 0.001 & $0.066^{* * *}$ & 0.010 \\
\hline$\alpha \mathrm{BOND}$ & $0.044 * * *$ & 0.002 & $0.044 * * *$ & 0.006 & $0.071^{* * *}$ & 0.009 \\
\hline$\beta B O N D$ & $0.955 * * *$ & 0.002 & $0.955^{* * *}$ & 0.005 & $0.915^{* * *}$ & 0.010 \\
\hline$\gamma \mathrm{BOND}$ & & & & & $1.072 * * *$ & 0.028 \\
\hline$\delta 1$ & $0.011 * * *$ & 0.002 & $0.011 * * *$ & 0.002 & $0.022 * * *$ & 0.004 \\
\hline$\delta 2$ & $0.984 * * *$ & 0.003 & $0.985^{* * *}$ & 0.003 & $0.931 * * *$ & 0.022 \\
\hline
\end{tabular}

Note. The two column for each parameter are their estimates and the Bollerslev and Wooldridge (1992) robust error. $* * *, * * *$ indicates the level of significance at $10 \%, 5 \%$ and $1 \%$,respectively.

For DCC and cDCC models, we use the two-step estimation method and specify the model follow the multivariate norm distribution and with AR (1) term in the mean equation. For bayesDCC models, we use the MCMC method to estimate the parameters coefficients, and the simulation number is equal to 10000 . Table 3 presents the estimated results of DCC, cDCC and bayesDCC models. We find that the estimated coefficients for both short-term persistence $(\alpha)$ and long-term persistence $(\beta)$ are statistically significance, and all return series meet the condition of $\alpha+\beta<1$. We can also find the estimations of $\delta 1$ and $\delta 2$ are both statistically significance and positive, and their sum of $\delta_{1}+\delta_{2}$ is also less than one. It indicates that the volatility process is mean-reverting and satisfy the positive definite condition. The coefficients are very close estimated by these three models, but the estimated standard errors of bayesDCC model is the smallest, follow by cDCC model. For bayesDCC model, the parameters $\gamma$ denotes the marginal skewness distribution of each variable, when $\gamma>1$ (or $\gamma<1)$ correspond to right (or left). The estimated result indicates the marginal skewness distribution of gas and bond are right, where as other assets are left, which are consist with the skewness values in Table 1 .
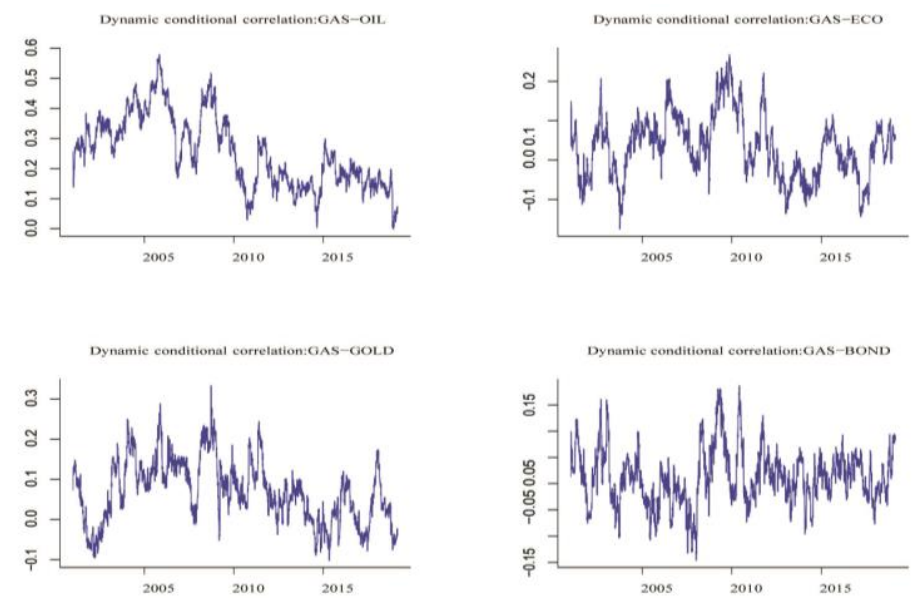

Figure 2. The plots of dynamic conditional correlations between GAS and other assets 
Figure 2 only shows the dynamic conditional correlation between nature gas returns and other assets returns by DCC model. It is obviously that the dynamic conditional correlation between natural gas market and crude oil market is greater than any other portfolios. To some extent, it implies that the crude oil may be the best instrument to hedge the natural gas's price risk.

\subsection{Optimal Hedging Performance}

Table 4 reports the comparative analysis of the hedge ratios and hedging effectiveness for each portfolio by these four models. Among the four pairs, GAS-OIL, GAS-ECO, GAS-GOLD and GAS-BOND exhibit positive mean hedge ratio values. The average hedging ratio of GAS-OIL portfolio is approximately equal to0.4 for each model. It means that a dollar long position in natural gas future can hedge about 40 cents short position in crude oil future. The hedge ratio of natural gas spot and crude oil in $\mathrm{Lin}$ and $\mathrm{Li}$ (2015) which calculate their average hedge ratio value is 0.159. For the GAS-ECO, GAS-GOLD, and GAS-BOND portfolio, the average OHRs are approximately equal to $0.06,0.2$ and 0.01 , respectively. That is to say, holding a short position in a GAS-OIL portfolio requires more natural gas futures contracts than other portfolios. For example, the largest average OHR value is 0.416 from bayesDCC model of GAS-OIL portfolio, suggesting that, if the short hedger want to minimize risk, when he buys a dollar gas future (long position) need to sell by about41.6 cents of OIL future (short position). For most of portfolio, the bayesDCC models have the best hedging performance, and the DCC and $\mathrm{CDCC}$ models have a similar hedging effectiveness values, and larger than the corresponding values of the CCC model.

Table 4. Descriptive statistical analysis of hedging ratio and hedging effectiveness (HE)

\begin{tabular}{lllll}
\hline & Mean & Min & Max & HE $\%$ \\
\hline GAS-OIL & & & & 6.720 \\
CCC & 0.414 & 0.117 & 1.251 & 7.837 \\
DCC & 0.406 & -0.083 & 1.584 & 7.830 \\
cDCC & 0.411 & -0.002 & 1.585 & 8.030 \\
baysDCC & 0.416 & 0.052 & 3.312 & 0.240 \\
GAS-ECO & & & 0.316 \\
CCC & 0.070 & 0.016 & 0.256 & 0.313 \\
DCC & 0.061 & -0.425 & 0.926 & 2.180 \\
cDCC & 0.066 & -0.429 & 1.023 & 0.586 \\
baysDCC & 0.159 & -2.940 & 2.615 & 0.621 \\
GAS-GOLD & & & 0.616 \\
CCC & 0.240 & 0.070 & 0.809 & 0.456 \\
DCC & -0.711 & 1.466 & 1.394 \\
cDCC & -0.573 & 1.558 & 0.003 \\
baysDCC & -2.061 & & -0.439 \\
GAS-BOND & 0.214 & & 0.135 & -0.437 \\
CCC & 0.172 & 0.007 & 0.500 & -7.025 \\
DCC & & -0.593 & 0.503 & 6.536 \\
cDCC & 0.030 & -0.566 & & \\
baysDCC & 0.012 & -0.804 & & \\
\hline
\end{tabular}

Figure 3 presents the time-varying OHRs which calculated from each multivariate conditional volatility models for each portfolio. Due to the OHR is determined by the second moment of each portfolio, so the different models will produce the difference of OHRs. We can see the OHRs which get from bayesDCC models are the most trend stationarity. Therefore, from a investor perspective, we suggest that the investor seeking high returns from natural gas market should consider combine it with crude oil to hedging the portfolio risk. This is mainly because GAS-OIL portfolio has the highest hedging effectiveness than other portfolios. Gold provides the second hedging effectiveness for natural gas, and ECO is the third best hedging effectiveness substitute. Note that in the GAS-BOND portfolio, some hedging effectiveness values are negative, indicating that the hedged portfolios are worse than the unhedged portfolio. 

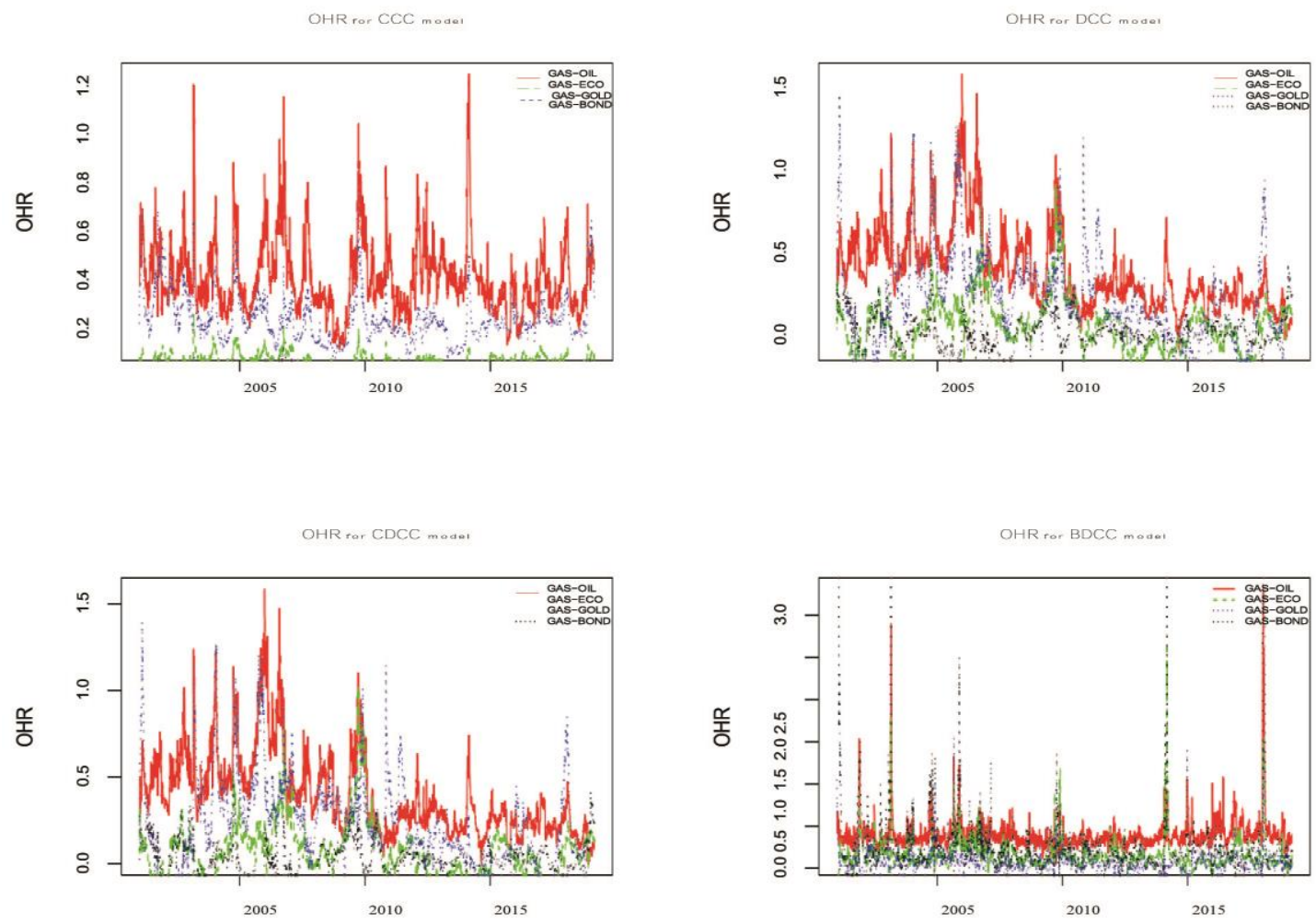

Figure 3. Optimal hedging ratio for multivariate models

\section{Conclusions}

This paper investigates the usefulness of using oil, ECO, gold and bonds to hedge an investment in natural gas employing four different multivariate GARCH models. One of the main works of this paper is that it compares the conditional correlations estimated from the CCC, DCC, cDCC and bayesDCC models. Then, the variance and covariance matrices of all models are extracted to calculate the optimal hedge ratios and hedging effectiveness. Meanwhile, we also compare the hedging effectiveness of different portfolios under different models, trying to seek the optimal hedging strategy.

Our findings suggest the following key points: First, hedge ratios vary widely over the sample period, which means they should be updated regularly. Second, among the selected hedging instruments, crude oil future is the best hedging asset for natural gas because it shows the highest hedging effectiveness under different scenarios. In most cases, gold and ECO are the second and third most effective hedging assets, respectively. Third, bayesDCC model provides a better hedging performance than other multivariate volatility models, the hedge ratios and hedging effectiveness calculated from DCC model or cDCC model are very similar in most cases, because the estimation process of DCC and $\mathrm{CDCC}$ model is not very different. The main take away from this paper is that crude oil provides the most effective hedge for natural gas followed by gold and ECO under our considered scenarios. This is a new result. We find that bonds are not particularly good hedges for natural gas because of their low hedging effectiveness.

Our results are of interest to current investors in natural gas as well as future investors in natural gas. There is already a growing movement among pension funds, university endowments and mutual funds toward divesting from fossil fuels. Divesting from fossil fuels creates opportunities to invest in other assets like natural gas. However, this paper also has some clear limitations. For future research, the sample period can be separated the crisis period and non-crisis time to discuss the hedging effectiveness under different background. In addition, future researchers might investigate different natural gas contract whether has new features of hedging effectiveness under different scenarios.

\section{Acknowledgements}

This work is supported by the Young Innovative Talents Program for Regular Institutions in Guangdong Province (2018WQNCX194). 


\section{Conicts of Interest}

The authors declare no conflict of interest.

\section{References}

Aielli, G. P. (2013). Dynamic conditional correlation: On properties and estimation. Journal of Business Economic Statistics, 31, 282-299. https: //doi.org/10.1080/07350015.2013.771027

Baillie, R. T., \& Myers, R. J. (1991). Bivariate garch estimation of the optimal commodity futures hedge. Journal of Applied Econometrics, 6, 109-124. https: //doi.org/10.1002/jae.3950060202

Bauwens, L., \& Laurent, S. (2005). A new class of multivariate skew densities, with application to generalized autoregressive conditional heteroscedasticity models. Journal of Business Economic Statistics, 23, 346-354. https: //doi.org/10.1198/073500104000000523

Bollerslev, T., \& Wooldridge, J. M. (1992). Quasi-maximum likelihood estimation and inference in dynamic models with time-varying covariances. Econometric Reviews, 11, 143-172. https://doi.org/10.1080/07474939208800229

Brinkmann, E. J., \& Rabinovitch, R. (1995). Regional limitations on the hedging effectiveness of natural gas futures. The Energy Journal, 113-124. https: //doi.org/10.2307/41322608

Chang, C. L., Mcaleer, M., \& Tansuchat, R. (2011). Crude oil hedging strategies using dynamic multivariate garch. Energy Economics, 33, 912-923. https: //doi.org/10.1016/j.eneco.2011.01.009

Chang, C. L., McAleer, M., \& Wang, Y. (2018). Testing co-volatility spillovers for natural gas spot, futures and etf spot using dynamic conditional covariances. Energy, 151, 984-997. https://doi.org/10.1016/j.energy.2018.01.017.

Chen, K. H. (2007). On the application of the dynamic conditional correlation model in estimating optimal time-varying hedge ratios. Applied Economics Letters, 14, 503-509. https://doi.org/10.1080/13504850500447331

Dickey, D. A., \& Fuller, W. A. (1979). Distribution of the estimators for autoregressive time series with a unit root. Journal of the American Statistical Association, 74, 427-431. https: //doi.org/10.2307/2286348

Egging, R., \& Holz, F. (2016). Risks in global natural gas markets: investment, hedging and trade. Energy Policy, 94, 468-479. https://doi.org/10.1016/j.enpol.2016.02.016

Engle, R. (2002). Dynamic conditional correlation: A simple class of multivariate generalized autoregressive conditional heteroskedasticity models. Journal of Business Economic Statistics, 20, 339-350. Retrieved from https://www.jstor.org/stable/1392121

Engle, R. F. (1982). Autoregressive conditional heteroscedasticity with estimates of the variance of United Kingdom inflation. Econometrica, 987-1007. https: //doi.org/ 10.2307/1912773

Engle, R. F., \& Kroner, K. F. (1995). Multivariate simultaneous generalized arch. Econometric Theory, 11, 122-150. Retrieved from https: //www.jstor.org/stable/3532933

Ergen, I., \& Rizvanoghlu, I. (2016). Asymmetric impacts of fundamentals on the natural gas futures volatility: An augmented garch approach. Energy Economics, 56, 64-74. https://doi.org/10.1016/j.eneco.2016.02.022

Fioruci, J. A., Ehlers, R. S., \& Filho, M. G. A. (2014). Bayesian multivariate garch models with dynamic correlations and asymmet- ric error distributions. Journal of Applied Statistics, 41, 320-331. https://doi.org/10.1080/02664763.2013.839635

Ghoddusi, H., \& Emamzadehfard, S. (2017). Optimal hedging in the us natural gas market: The effect of maturity and cointegration. Energy Economics, 63, 92-105. https://doi.org/10.1016/j.eneco.2017.01.018.

Hailemariamcs, A., \& Smyth, R. (2019). What drives natural gas prices? Energy $\quad$ Economics, $\quad 80, \quad 731-742$. https://doi.org/10.1016/j.eneco.2019.02.011

Jarque, C. M., \& Bera, A. K. (1980). Efficient tests for normality, homoscedasticity and serial independence of regression residuals. Economics letters, 6, 255-259. https: //doi.org/10.1016/0165-1765(80)90024-5

Johnson, L. L. (1960). The theory of hedging and speculation in commodity futures. Review of Economic Studies, 27, 139-151. https: //doi.org/10.1007/978-1-349-02693-7_4

Kroner, K. F., \& Ng, V. K. (1998). Modeling asymmetric comovements of asset returns. Review of Financial Studies, 11, 817-844. https: //doi.org/10.1093/ rfs/11.4.817 
Kwiatkowski, D., Phillips, P. C., Schmidt, P., \& Shin, Y. (1992). Testing the null hypothesis of stationarity against the alternative of a unit root: How sure are we that economic time series have a unit root? Journal of Econometrics, 54, 159-178. https: //doi.org/10.1016/0304-4076(92)90104-Y

Lin, B., \& Li, J. (2015). The spillover effects across natural gas and oil markets: Based on the vec-mgarch framework. Applied Energy, 155, 229-241. https://doi.org/10.1016/j.apenergy.2015.05.123

Lin, L., Zhou, Z., Liu, Q., \& Jiang, Y. (2019). Risk transmission between natural gas market and stock markets: portfolio and hedging strategy analysis. Finance Research Letters, 29, 245-254. https://doi.org/10.1016/j.frl.2018.08.011.

Ljung, G. M., \& Box, G. E. (1978). On a measure of lack of fit in time series models. Biometrika, 65, 297-303. https: //doi.org/10.1093/biomet/65.2.297

Mart'inez, B., \& Torr'o, H. (2015). European natural gas seasonal effects on futures hedging. Energy Economics, 50, 154-168. https://doi.org/10.1016/j.eneco.2015.04.002.

Nick, S., \& Thoenes, S. (2014). What drives natural gas prices? - a structural var approach. Energy Economics, 45, 517-527. https://doi.org/10.1016/j.eneco.2014.08.010

Phillips, P. C., \& Perron, P. (1988). Testing for a unit root in time series regression. Biometrika, 75, 335-346. https: //doi.org/10.1093/biomet/75.2.335

Susmel, R., \& Thompson, A. (1997). Volatility, storage and convenience: Evidence from natural gas markets. The Journal of Futures Markets (1986-1998), 17, 17. Retrieved from https://EconPapers.repec.org/RePEc:wly:jfutmk:v:17:y:1997:i:1:p:17-43

Van Goor, H., \& Scholtens, B. (2014). Modeling natural gas price volatility: The case of the uk gas market. Energy, 72, 126-134. https://doi.org/10.1016/j.energy.2014.05.016

Wang, T., Zhang, D., \& Broadstock, D. C. (2019). Financialization, fundamentals, and the time-varying determinants of us natural gas prices. Energy Economics, 80, 707-719. https://doi.org/10.1016/j.eneco.2019.01.026.

\section{Note}

Note 1. we re-exampled the bond by Ljung and Box (1978) Q2(1) and Q2(10), the result show no autocorrelation.

\section{Copyrights}

Copyright for this article is retained by the author(s), with first publication rights granted to the journal.

This is an open-access article distributed under the terms and conditions of the Creative Commons Attribution license (http://creativecommons.org/licenses/by/4.0/). 